\title{
Fast pyrolysis of heavy metal contaminated willow: Influence of the plant part
}

\author{
C. Lievens, R. Carleer* ${ }^{*}$ T. Cornelissen, J. Yperman \\ Lab. of Applied and Analytical Chemistry, CMK, University Hasselt Building D, Agoralaan, 3590 Diepenbeek, Belgium
}

\section{A R T I C L E I N F O}

\section{Article history:}

Received 17 April 2008

Received in revised form 28 January 2009

Accepted 3 February 2009

Available online 27 February 2009

\section{Keywords:}

Fast pyrolysis

Biomass plant part

Gas fraction

TD/GC/MS

TG/FT-IR

\begin{abstract}
A B S T R A C T
Fast pyrolysis of heavy metal contaminated willow, with high concentrations of $\mathrm{Cd}, \mathrm{Cu}, \mathrm{Pb}$ and $\mathrm{Zn}$, resulting from phytoremediation, is investigated. The distribution of the heavy metals depends on the plant part (leaves and branches). Nevertheless, their individual pyrolysis fractions (at an operational temperature of $623 \mathrm{~K}$ ), i.e., bio-oil/tar and gas, are both heavy metal free. Some small differences in the kind and amounts of the organic compounds are found in the bio-oil and gaseous fraction. In view of practical considerations leaves and branches should nevertheless be pyrolysed simultaneously. The use of hyphenated thermal analytical techniques allows obtaining more detailed information on the compositional features of the pyrolysis fraction.
\end{abstract}

(c) 2009 Elsevier Ltd. All rights reserved.

\section{Introduction}

Because of the global climate changes, environmental pollution $\left(\mathrm{NO}_{x}, \mathrm{SO}_{x}, \mathrm{CO}_{2}\right)$ and the decrease of accessibility of fossil energy resources, renewable energy is of growing importance. Biomass as waste, however, is a clean and renewable energy source. It is also abundant and stands as the third energy resource after oil and coal [1]. Biomass has the extra advantage, in the form of plants, that it also can be used as remediation of heavy metal contaminated soils.

Meers et al. [2] discussed willow as a short rotation coppice for phytoremediation of contaminated sites and simultaneous generation of bio-energy by conversion of the produced biomass. Five species of Salix spp. in their ability to extract and accumulate heavy metals $(\mathrm{Cd}, \mathrm{Cr}, \mathrm{Cu}, \mathrm{Ni}, \mathrm{Pb}, \mathrm{Zn})$ in harvestable plant parts were discussed.

Direct combustion of biomass has been carried out worldwide since the ancient times for cooking and heating. However, problems can arise during burning of biomass containing high amounts of heavy metals without any pre-treatment. Therefore, some thermal conversion methods such as pyrolysis, gasification, and carbonization to produce fuel products are more preferable to the direct combustion of biomass.

The pyrolysis process of biomass is highly complex and depends on several factors such as composition of lignocellulosic material, heating rate, content of inorganic material, etc. The main elemental constituents of biomass minerals are $\mathrm{Si}, \mathrm{K}, \mathrm{Ca}$ and $\mathrm{Mg}$ with minor amounts of S, P, Fe, Al and Mn [3].

\footnotetext{
* Corresponding author. Tel.: +32 11 268320; fax: +32 11268301.

E-mail address: robert.carleer@uhasselt.be (R. Carleer).
}

Pyrolysis of willow has been the subject of many investigations. Flash co-pyrolysis of biomass (willow) and PLA (poly lactic acid) or PHB (poly hydroxyl butyric acid) is a potential method in reducing the high amounts of water in bio-oil, one of the drawbacks of using bio-oil as a fuel [4,5]. Short rotation willow coppice (SRC) and a synthetic biomass, a mixture of the basic biomass components (cellulose, hemi cellulose and lignin), have been investigated for the influence of potassium on their pyrolysis behaviours [3]. A comparison of product distributions and kinetics were reported.

In this study heavy metal contaminated willow (sampled in the north-east of Belgium), and resulting from a phytoremediation project is subjected to fast pyrolysis at $623 \mathrm{~K}$. Distinction has been made between two plant parts: leaves and branches. The rationale for using this approach as the method of choice is (a) the reduction in volume and weight of heavy metal contaminated biomass, (b) energy/chemical recovery in the form of liquid and gaseous products produced from the pyrolysis operation, (c) production of a char/ash residue that recovers the metals in the form of a metal concentrate that may be processed commercially.

The objective of this study is to perform fast pyrolysis of willow, contaminated with heavy metals ( $\mathrm{Cd}, \mathrm{Cu}, \mathrm{Pb}$, and $\mathrm{Zn}$ ) in a lab scale reactor to produce a metal concentrate in the char/ash fraction, by documenting the metal component material balances and by studying the distribution of the heavy metals in the product streams at $623 \mathrm{~K}$. Parameter under investigation is the plant part: contaminated willow leaves (CWL) and branches (CWB). Furthermore, the kinetics and the size of the pyrolysis fractions of both plant parts at $623 \mathrm{~K}$, will be investigated, by thermogravimetry. Subsequently, the condensable fractions will be characterised by their higher heating values and TG/FTIR and GC/MS for their 
compositional features; the non-condensable pyrolysis fractions will be characterized by TG/FTIR and TD/GC/MS.

\section{Materials and methods}

\subsection{Materials and samples preparation}

The heavy metal contaminated willow leaves (CWL) and branches (CWB) are investigated, and collected from a site, heavily polluted with $\mathrm{Cd}, \mathrm{Cu}, \mathrm{Pb}$, and $\mathrm{Zn}$, in the province of Limburg in Belgium. Prior to use, the biomass is air dried, ground in a high-speed rotary cutting mill and then sieved (diameter $<2 \mathrm{~mm}$ ). There is opted for the use of a solid heat carrier for improving the heat transfer in the reactor [6]: fumed silica (Sigma; $0.007 \mu \mathrm{m} ; 390 \pm 40 \mathrm{~m}^{2} /$ $\mathrm{g})$. The heavy metal concentrations and mineral content of CWL and CWB are determined with an Perkin Elmer OPTIMA 3000 DV ICP/AES after full destruction of the material with $\mathrm{HClO}_{4}$ (70\% p.a. Merck) $-\mathrm{HNO}_{3}$ (65\% s.p. J.T. Baker) mixture. The resulting ash product of CWL and CWB is dissolved in a $10 \% \mathrm{HNO}_{3}$ solution. The amount of free water and ash content is determined thermogravimetrically (TG) at 378 and $773 \mathrm{~K}$, respectively, $[7,8]$. The ultimate analysis of the different plant parts and pyrolysis products (oilwater free and tar) is determined with an elemental analyzer EA (Flash EA 1112 series Thermo Electron Corporation, Interscience). A certified standard is used: BBOT (2,5 bis(5-tert-butyl-benzoxazol-2-yl) thiophene $\mathrm{C}_{26} \mathrm{H}_{26} \mathrm{~N}_{2} \mathrm{O}_{2} \mathrm{~S}$ ) (Thermo Electron Corporation)). The oxygen content is determined out of the difference. The higher heating values (HHV) of CWL and CWB, and their liquid pyrolysis products (water free), are determined in two different ways: calculated $[9,10]$ and experimentally [11]. Chlorides ions are determined by ion chromatography (Dionex DX120 ion chromatograph) with a conductivity detector. In order to determine the total chloride content, the CWL and CWB samples are combusted in an $\mathrm{O}_{2}$ atmosphere in a Parr bomb. The absorption liquid is a $\mathrm{Na}_{2} \mathrm{CO}_{3}(2.5 \%)$ solution.

\subsection{Pyrolysis set-up}

The pyrolysis experiments were performed at $623 \mathrm{~K}$. The temperature of $623 \mathrm{~K}$ is based on the temperature of maximum decomposition obtained from TG analysis (Fig. 1a and b). The pyrolysis experiments are performed with a $3 \mathrm{~g}$ of biomass feedstock, mixed with fumed silica ( $\sim 0.5 \mathrm{~g})$, in a horizontal tube reactor (Nabertherm), constructed in quartz with a heating rate of $35 \mathrm{~K} / \mathrm{min} ; \mathrm{N}_{2}$ is used as sweep gas $\left(30 \mathrm{~cm}^{3} / \mathrm{min}\right)$. The quantity of solid heat carrier chosen, to obtain an optimum heat transfer and to prevent clothing, is a $1 / 1$ volume ratio of a mixture of biomass and fumed silica. The process parameters and the pyrolysis set-up have been reported earlier [12]. The pyrolysis products can be divided in three phases: solid, liquid and gas. The solid fraction consists of a char fraction and the ash fraction. The liquid phase consists of a tar phase and a bio-oil phase. The bio-oil phase consists of a heterogeneous water/oil mixture. Pyrolytic water is determined, by azeotropic distillation of bio-oil phase with toluene, in a Dean and Stark apparatus. The gas phase consists of gaseous non-condensable gases evolved during pyrolysis $(T>423 \mathrm{~K})$ and the moisture of the biomass $(T<423 \mathrm{~K})$. The char (together with ash), tar and bio-oil fractions are weighed. The gas yield is calculated from the material balance by difference.

\subsection{Heavy metal distribution determination}

The char, tar and bio-oil fractions, are digested in an $\mathrm{HClO}_{4}-$ $\mathrm{HNO}_{3}$ solution for heavy metal determination. Fumed silica is destructed by HF (40\% s.p Merck). All these digestion solutions are evaporated $(T=423-473 \mathrm{~K})$ and dissolved in a solution of $10 \%$ $\mathrm{HNO}_{3}$ up to a volume of $25 \mathrm{ml}$. All the reactor ware is rinsed afterwards with small quantities of a solution of $10 \% \mathrm{HNO}_{3}$, which is also analysed for heavy metals. An overall uncertainty is estimated and accepted around 10-30\%, which includes errors during the pyrolysis process, sample preparation and ICP measurements (minor). All the results have been statistically processed according to Mood et al. [13].

\subsection{Thermogravimetric analysis (TGA)}

Information about the thermal degradation of the different plant parts can be obtained by thermogravimetry. The measurements are carried out with a TA Instruments 951 Thermogravimetric Analyzer. Samples of $20 \mathrm{mg}$ are placed in a quartz sample pan and flushed with $\mathrm{N}_{2}$ carrier gas $\left(30 \mathrm{~cm}^{3} / \mathrm{min}\right)$. The samples were heated at $35 \mathrm{~K} / \mathrm{min}$ up to $923 \mathrm{~K}$.

\subsection{Thermogravimetry Fourier transfer infra-red spectrometry (TG/FTIR)}

The TG/FTIR instrument consists of a TA Instruments 951 Thermogravimetric Analyzer interfaced with a Bruker IFS 48 FTIR spectrometer. Samples of $20 \mathrm{mg}$ are placed in a quartz sample pan and flushed with $\mathrm{N}_{2}$ carrier gas $\left(30 \mathrm{~cm}^{3} / \mathrm{min}\right)$. The samples are heated at $35 \mathrm{~K} / \mathrm{min}$ up to $923 \mathrm{~K}$. The volatile products are transferred continuously towards a heated gas cell $(473 \mathrm{~K})$ into the FTIR spectrometer through an interface heated to $473 \mathrm{~K}$. The used detector in combination with the gas cell is a mercury-cadmium-tellurium (MCT) photo conductive cell, cooled by liquid nitrogen. The optical windows of the gas cell are manufactured out of $\mathrm{KBr}$. The measurements are conducted between 4000 and $650 \mathrm{~cm}^{-1}$ with a resolution of $16 \mathrm{~cm}^{-1}$.
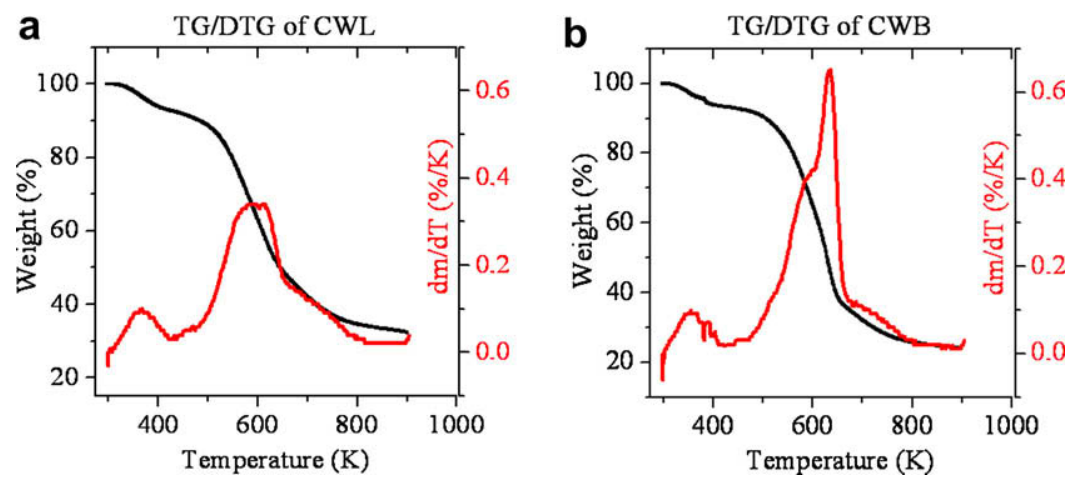

Fig. 1. TG/DTG of CWL (a) and CWB (b). 


\subsection{Gas chromatography/mass spectrometry (GC/MS)}

The bio-oil/tar fractions obtained at $623 \mathrm{~K}$ are dissolved in dichloromethane (p.a. Merck; number 106054; 1/100) and analyzed by GC/MS, together with an internal standard (100 ng hexachlorobenzene). The GC/MS instrument consists of Finnigan TSQ-700, with $\mathrm{He}$ ( $85 \mathrm{kPa}$ inlet pressure) as the carrier gas and a capillary column $(30 \mathrm{~m}$ CPsil8MS $\times 0.32 \mathrm{~mm}$ i.d.; $0.25 \mu \mathrm{m}$ film thickness (Varian)). The injection port and transfer line are both operated at $553 \mathrm{~K}$. The GC oven is heated from $308 \mathrm{~K}$ for $1 \mathrm{~min}$, to $593 \mathrm{~K}$ at a rate of $15 \mathrm{~K} / \mathrm{min}$ and a $6 \mathrm{~min}$ isothermal period. The injection volume, used for analysis, is $1 \mu \mathrm{l}$. Spectra are recorded in $\mathrm{EI}+$ mode (electron energy $=70 \mathrm{eV}$ ), with a scan range from 45 to $550 \mathrm{~m} / \mathrm{z}$ in $0.5 \mathrm{~s}$.

\subsection{Thermal desorption/gas chromatography/mass spectrometry (TD/GC/MS)}

Thermal desorption GC/MS (TD/GC/MS) analysis is used for a semi-quantitative study of volatile organic collected on a tenax adsorbance during the pyrolysis of CWL and CWB. Pyrolysis of the biomass (sample $\sim 1 \mathrm{~g}$ ) mixed with a silica matrix $(\sim 0.5 \mathrm{~g})$ is performed. The heating rate is $35 \mathrm{~K} / \mathrm{min}$, with $\mathrm{N}_{2}$ as sweep gas with a flow rate of $30 \mathrm{~cm}^{3} / \mathrm{min}$. The carrier gas stream is sampled after the condensation system at the following temperature intervals: 373-473 K, 473-573 K, 573-673 K, 673-773 K and 773-873 K by Tenax $^{\circledR}$-TA tubes (60-80 Alltech). The thermal desorption of the Tenax tubes are carried out on Markes Unity (20 min desorption at $583 \mathrm{~K}$ ) and analyzed by GC/MS. Raw quantification is performed to $3 \mu \mathrm{g}$ dodecane as external standard. The GC/MS instrument consists of Finnigan-Thermo Trace DSQ, with $\mathrm{He}(85 \mathrm{kPa}$ inlet pressure) as the carrier gas and a capillary column $(30 \mathrm{~m}$ CPsil8MS $\times 0.25 \mathrm{~mm}$ i.d.; $0.5 \mu \mathrm{m}$ film thickness (Varian)). The GC oven is heated from $308 \mathrm{~K}$ for $5 \mathrm{~min}$ then to $373 \mathrm{~K}$ at a rate of $8 \mathrm{~K} / \mathrm{min}$, then to $553 \mathrm{~K}$ at a rate of $12 \mathrm{~K} / \mathrm{min}$ and an isothermal period of $5 \mathrm{~min}$. Spectra are recorded in $\mathrm{EI}+$ mode (electron energy = $70 \mathrm{eV}$ ), with a scan range from 33 to $470 \mathrm{~m} / \mathrm{z}$ in $0.5 \mathrm{~s}$.

\section{Results and discussion}

\subsection{Characterisation and pyrolysis kinetics of CWL and CWB}

Table 1 gives the heavy metal and mineral content of CWL and CWB. Table 2 shows the main characteristics of CWL and CWB. The $\mathrm{HHV}$ of CWL is 7\% lower than the calorific value of CWB. The calculated HHV of CWL and CWB are higher than the experimentally determined calorific values. By comparing the (D)TG data of CWL and CWB it can be concluded that every biomass plant part has its own typical decomposition characteristics as seen Fig. 1a and b.

Table 1

Mineral and heavy metal content $(\mu \mathrm{g} / \mathrm{g})$ in CWL and CWB.

\begin{tabular}{lcc}
\hline$\mu \mathrm{g} / \mathrm{g}$ & $\mathrm{CWL}$ & $\mathrm{CWB}$ \\
\hline Mineral content & & \\
$\mathrm{Al}$ & $44 \pm 4$ & $18 \pm 2$ \\
$\mathrm{Ca}$ & $18330 \pm 530$ & $6740 \pm 1040$ \\
$\mathrm{Fe}$ & $85 \pm 26$ & $13 \pm 12$ \\
$\mathrm{~K}$ & $6420 \pm 200$ & $1970 \pm 170$ \\
$\mathrm{Mg}$ & $930 \pm 95$ & $3030 \pm 160$ \\
$\mathrm{Mn}$ & $101 \pm 6$ & $13 \pm 3$ \\
$\mathrm{Na}$ & $585 \pm 30$ & $62 \pm 14$ \\
$\mathrm{Heavy}$ metals & & \\
$\mathrm{Cd}$ & $55 \pm 2$ & $27 \pm 2$ \\
$\mathrm{Cu}$ & $15 \pm 1$ & $8 \pm 1$ \\
$\mathrm{~Pb}$ & $13 \pm 1$ & $5 \pm 0.4$ \\
$\mathrm{Zn}$ & $4500 \pm 50$ & $656 \pm 74$ \\
\hline
\end{tabular}

Table 2

Main characteristics of CWL and CWB.

\begin{tabular}{|c|c|c|}
\hline & CWL & CWB \\
\hline Moisture (w/w\%) & $12 \pm 1$ & $10 \pm 0.4$ \\
\hline $\operatorname{Ash}(w / w \%)^{a}$ & $12 \pm 1$ & $3.4 \pm 0.5$ \\
\hline \multicolumn{3}{|c|}{ Ultimate analysis $(\mathrm{w} / \mathrm{w} \%)^{\mathrm{a}}$} \\
\hline C & $41.9 \pm 0.6$ & $45.5 \pm 0.6$ \\
\hline $\mathrm{H}$ & $5.7 \pm 0.01$ & $6.1 \pm 0.04$ \\
\hline $\mathrm{N}$ & $2.1 \pm 0.01$ & $0.7 \pm 0.3$ \\
\hline $\mathrm{S}$ & $0.9 \pm 0.1$ & $<\mathrm{DL}$ \\
\hline $\mathrm{O}^{\mathrm{b}}$ & $37.8 \pm 0.5$ & $44.0 \pm 0.8$ \\
\hline HHV (MJ/kg) & $17 \pm 0.3$ & $18 \pm 0.3$ \\
\hline \multicolumn{3}{|l|}{ Calculated } \\
\hline Experimentally & $14 \pm 1$ & $16 \pm 2$ \\
\hline $\mathrm{Cl}^{-}(\mu \mathrm{g} / \mathrm{g})$ & $4650 \pm 450$ & $150 \pm 45$ \\
\hline
\end{tabular}

$\mathrm{DL}=$ detection limit.

a Weight percentage on dry basis.

b By difference, ash content taken into consideration.

CWL starts to decompose at $423 \mathrm{~K}$ and CWB at $473 \mathrm{~K}$. The second maxima in the DTG of CWL and CWB are at 600 and $630 \mathrm{~K}$, resp. The maximum rate of decomposition of $\mathrm{CWL}$ is $0.35 \% / \mathrm{K}$, which is only half of the maximum rate of decomposition of CWB $(0.65 \% / K)$. These phenomena and the difference in reactivity can be explained by variations (mineral and organic) in the build-up of CWL and CWB [14-16].

\subsection{Influence of the plant part on the product yields}

The pyrolysis fractions of CWL and CWB at $623 \mathrm{~K}$ are given in Table 3. Pyrolysis of CWB at $623 \mathrm{~K}$ results in somewhat larger char fraction (46\%) compared to CWL (42\%) under the same conditions. The largest differences in pyrolysis fractions distribution between CWL and CWB are found in the liquid fraction. The tar fraction of CWL (9\%) is twice the tar fraction of CWB (4\%) and the bio-oil (oil and pyrolytic water) fraction of CWB (36\%) is larger than the CWL pyrolysis bio-oil (25\%) produced at $623 \mathrm{~K}$. The liquid phase (bio-oil and tar) of CWL is $34 \%$ of the pyrolysis products and $40 \%$ for CWB. The collected organic volatiles on tenax adsorbents of CWL and CWB after pyrolysis at $623 \mathrm{~K}$ amount to approximately $1 \%$ of the gas fraction.

3.3. Influence of plant part on the distribution of heavy metals in the pyrolysis fractions

The concentration of $\mathrm{Cd}, \mathrm{Cu}, \mathrm{Pb}$, and $\mathrm{Zn}$ in $\mathrm{CWL}$ and $\mathrm{CWB}$ pyrolysis products at $623 \mathrm{~K}$, with digestion of the fumed silica matrix, is shown in Table 4 . The condensable and non-condensable pyrolysis fraction of CWL and CWB, produced at $623 \mathrm{~K}$, contain no detectable concentrations of $\mathrm{Cd}, \mathrm{Cu}$, and $\mathrm{Pb}$ compounds. The zinc compounds in CWL and CWB seem to be largely thermally stable during the pyrolysis of these biomasses, because only very small $(<1 \%)$ zinc

Table 3

The pyrolysis fractions (w/w\%) of CWL and CWB at $623 \mathrm{~K}$.

\begin{tabular}{lll}
\hline Fraction & CWL & CWB \\
\hline Solid (w/w\%) & & \\
$\quad$ Char & $42.4 \pm 8.1$ & $45.7 \pm 5.9$ \\
Ash & $11.6 \pm 0.6$ & $3.4 \pm 0.5$ \\
Liquid (w/w\%) & & \\
Tar & $9.0 \pm 2.6$ & $4.3 \pm 0.4$ \\
Oil & $5.7 \pm 2.7$ & $13.7 \pm 4.2$ \\
Water & $19.2 \pm 0.7$ & $22.3 \pm 0.9$ \\
Gas (w/w\%) & $<1$ & $<1$ \\
$\quad$ Gas & $12.3 \pm 0.5$ & $9.9 \pm 0.4$ \\
Moisture & & \\
\hline
\end{tabular}

"Obtained by difference. 
Table 4

Heavy metals in CWL and CWB $(\mu \mathrm{g} / \mathrm{g})$ pyrolysis products.

\begin{tabular}{lllllll}
\hline$\mu \mathrm{g} / \mathrm{g}$ & $623 \mathrm{~K}$ & Gas & Oil & Tar & Char & Original \\
\hline $\mathrm{Cd}$ & $\mathrm{CWL}$ & $<0.04$ & $<0.10$ & $<0.50$ & $50 \pm 13$ & $55 \pm 2$ \\
& $\mathrm{CWB}$ & $<0.04$ & $<0.10$ & $<0.10$ & $27 \pm 7$ & $27 \pm 2$ \\
$\mathrm{Cu}$ & $\mathrm{CWL}$ & $<0.04$ & $<0.10$ & $<0.10$ & $14 \pm 2$ & $15 \pm 1$ \\
& $\mathrm{CWB}$ & $<0.04$ & $<0.10$ & $<0.10$ & $8 \pm 1$ & $8.3 \pm 0.6$ \\
$\mathrm{~Pb}$ & $\mathrm{CWL}$ & $<0.20$ & $<0.50$ & $<0.50$ & $10 \pm 2$ & $12.8 \pm 0.5$ \\
& $\mathrm{CWB}$ & $<0.20$ & $<0.50$ & $<0.50$ & $4.1 \pm 0.6$ & $4.6 \pm 0.4$ \\
$\mathrm{Zn}$ & $\mathrm{CWL}$ & $<0.04$ & $<0.10$ & $1-2$ & $4225 \pm 600$ & $4503 \pm 53$ \\
& $\mathrm{CWB}$ & $<0.04$ & $0.49 \pm 0.16$ & $0.71 \pm 0.15$ & $720 \pm 42$ & $656 \pm 74$ \\
\hline
\end{tabular}

concentrations are detected in the condensable pyrolysis fractions of both CWL and CWB. The enrichment of the heavy metals in the char/ash fraction is thus an advantage, because the non- and condensable pyrolysis fractions are kept heavy metal free at $623 \mathrm{~K}$.

\subsection{Characterisation of the volatile fraction of CWL and CWB: TG/FTIR}

Figs. 2a and 2b show the CWL and CWB 3D plots of the different IR spectra of the released volatiles obtained during the pyrolysis of CWL and CWB, respectively, as a function of the temperature. The interpretation and characterization of the 3D plot will be explained with TG/FTIR data. Table 5 gives an overview of the IR bands assigned to the volatile pyrolysis fraction of CWL and CWB. The evolution of some of the functional groups within this fraction,

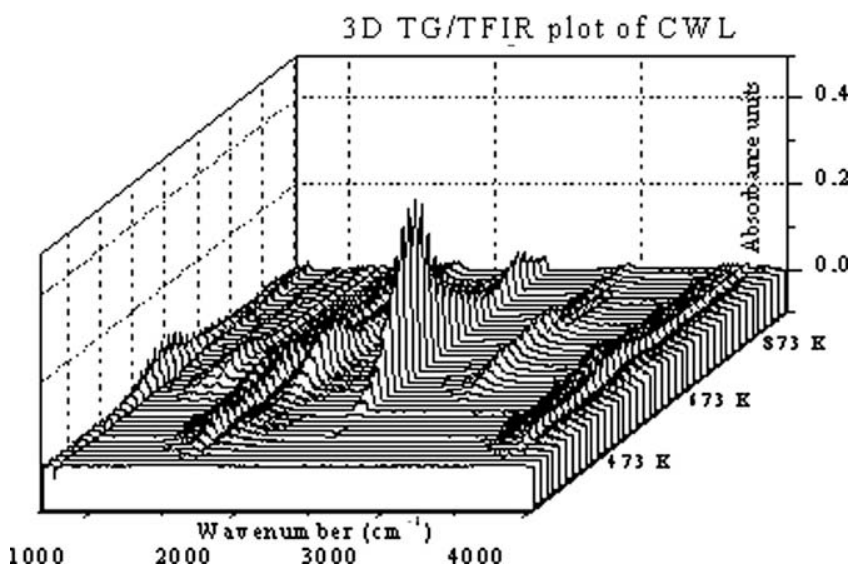

Fig. 2a. TG/FTIR 3D plot of CWL.

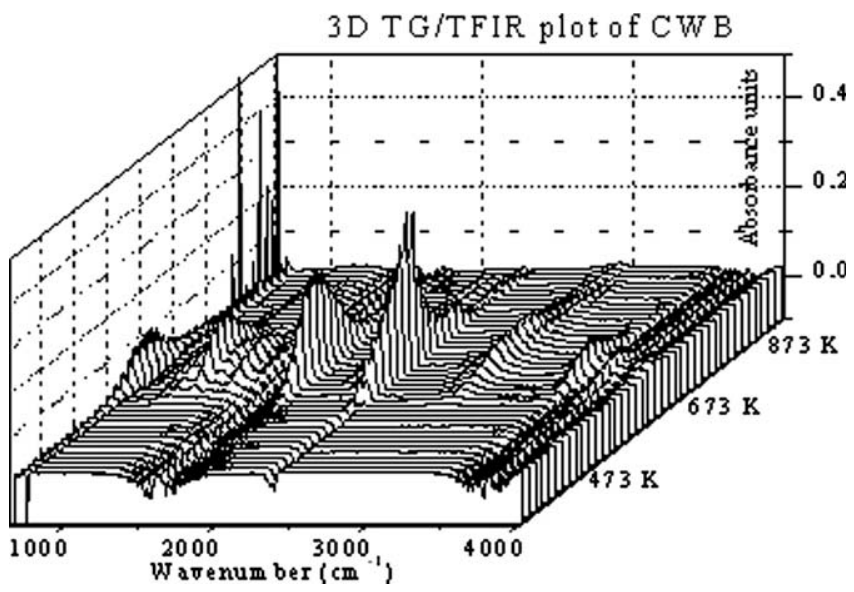

Fig. 2b. TG/FTIR 3D plot of CWB.
Table 5

Functional groups in the volatile fractions of CW.

\begin{tabular}{ll}
\hline Wavenumber range $\left(\mathrm{cm}^{-1}\right)$ & Functional group \\
\hline $3550-3900$ & Water, OH \\
$2990-3040$ & Aromatic and unsaturated C-C, C-H \\
$2800-3000$ & C-H vibrations, saturated C-C, C-H \\
$2250-2440$ & $\mathrm{O}=\mathrm{C}=\mathrm{O}$ \\
$2020-2230$ & $\mathrm{C}=\mathrm{O}$ \\
$1650-1800$ & Carbonyl \\
$1575-1675$ & $\mathrm{C}=\mathrm{C}$ stretching \\
$1000-1250$ & $\mathrm{C}-\mathrm{O}$ stretching \\
$680-900$ & Mono- and di-substituted benzene rings
\end{tabular}

expressed as the overall intensity within a specific spectral window, as a function of the temperature, is discussed.

IR absorption bands can be found, in the 3D plot of the different IR spectra of CWL and CWB (Fig. 3a), as a function of the temperature, dedicated to water or alcohols, between 3400 and $3900 \mathrm{~cm}^{-1}$, and to ethers and alcohols between $1000-1250 \mathrm{~cm}^{-1}$. Several absorption peaks can be found, representing $\mathrm{C}-\mathrm{O}$ stretching, which arise at $473 \mathrm{~K}(\mathrm{CWL})$ and $493 \mathrm{~K}(\mathrm{CWB})$ and show a maximum at $573 \mathrm{~K}$ and between 613 and $633 \mathrm{~K}$, for CWL and CWB, respectively. Fig. 4 shows that the evolution of water $\left(3660-3780 \mathrm{~cm}^{-1}\right.$ spectral window) with two distinct maxima: around $430 \mathrm{~K}$ and at 590 and $640 \mathrm{~K}$ for CWL and CWB, respectively. The first maximum can be assigned to the loss of free water and the second to dehydration reactions, as a result of pyrolysis, which starts around $380 \mathrm{~K}$ (pyrolytic water).

IR bands in the 1650 and $1820 \mathrm{~cm}^{-1}$ spectral window can be assigned to compounds with carbonyl functionalities (Fig. 3b). The release of pyrolysis compounds of CWL and CWB with carbonyl functionalities starts at $525 \mathrm{~K}$ and reaches their maximum around 620 and $610 \mathrm{~K}$, for CWL and CWB, respectively. Typical compounds with carbonyl function can be assigned to aldehydes, ketones, acids and esters. The presence of esters in the volatile pyrolysis products of CWL and CWB, is supported through broad absorption bands, found in $1730-1760 \mathrm{~cm}^{-1}$ spectral window (no separate Figure shown), which are first detected around $493 \mathrm{~K}$ and reach their maxima around $598 \mathrm{~K}(\mathrm{CWL})$ and $633 \mathrm{~K}(\mathrm{CWB})$.

IR absorption bands around $2350 \mathrm{~cm}^{-1}$ and in the 2000$2200 \mathrm{~cm}^{-1}$ spectral window are characteristic for the pyrolysis products $\mathrm{CO}_{2}$ and $\mathrm{CO}$, respectively, (Figs. 3c and 3d). Decarboxylation reactions for $\mathrm{CWL}$ with the release of carbon dioxide (Fig. 3c) start around $440 \mathrm{~K}$ and reach two maxima, a major at $590 \mathrm{~K}$ and a minor at $860 \mathrm{~K}$, and a shoulder at $720 \mathrm{~K}$. The shoulder and second maximum can be explained by the breakdown of primary pyrolysis products of $\mathrm{CWL}$, together with the formation of $\mathrm{CO}_{2}$.

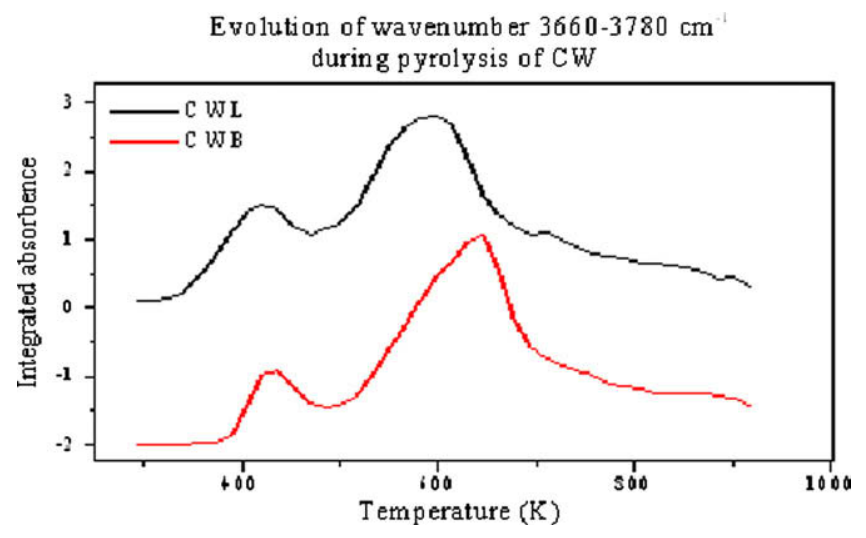

Fig. 3a. Evolution of water during the pyrolysis of CWL and CWB. 


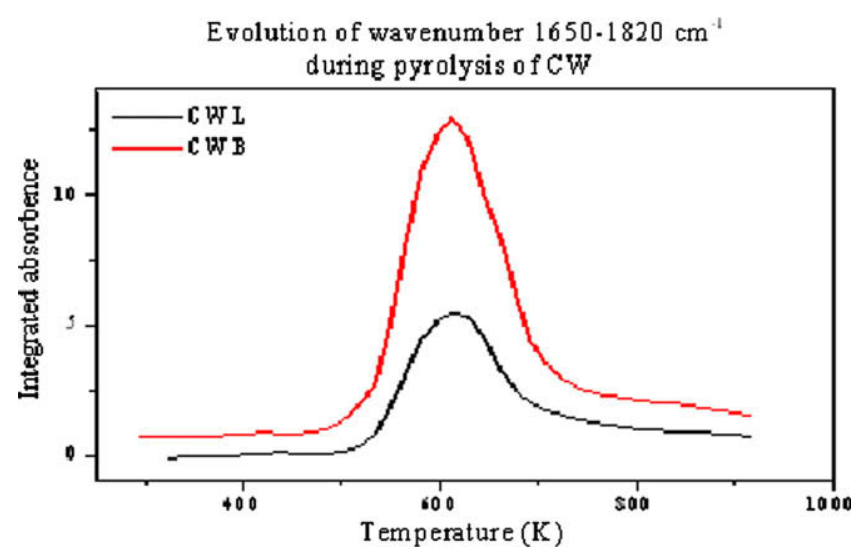

Fig. 3b. Evolution of carbonyl compounds during the pyrolysis of CWL and CWB.

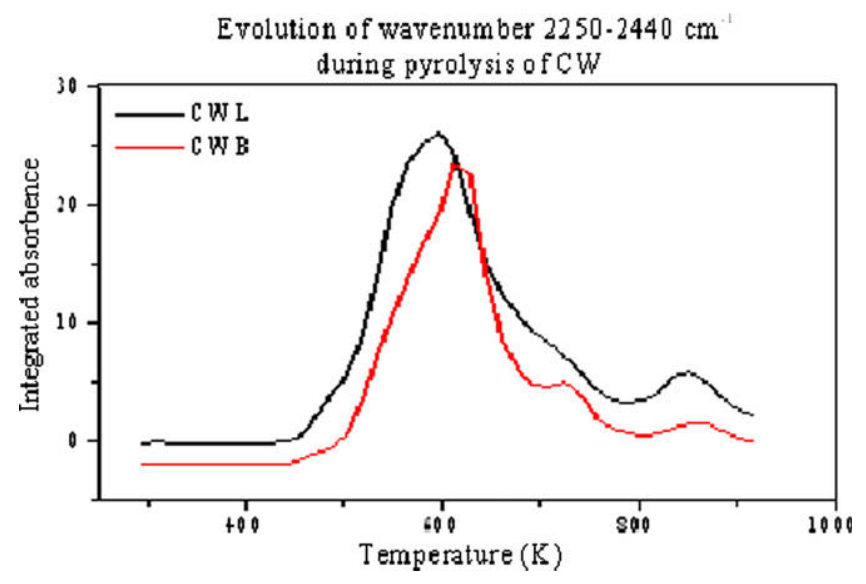

Fig. 3c. Evolution of $\mathrm{CO}_{2}$ during the pyrolysis of $\mathrm{CWL}$ and $\mathrm{CWB}$.

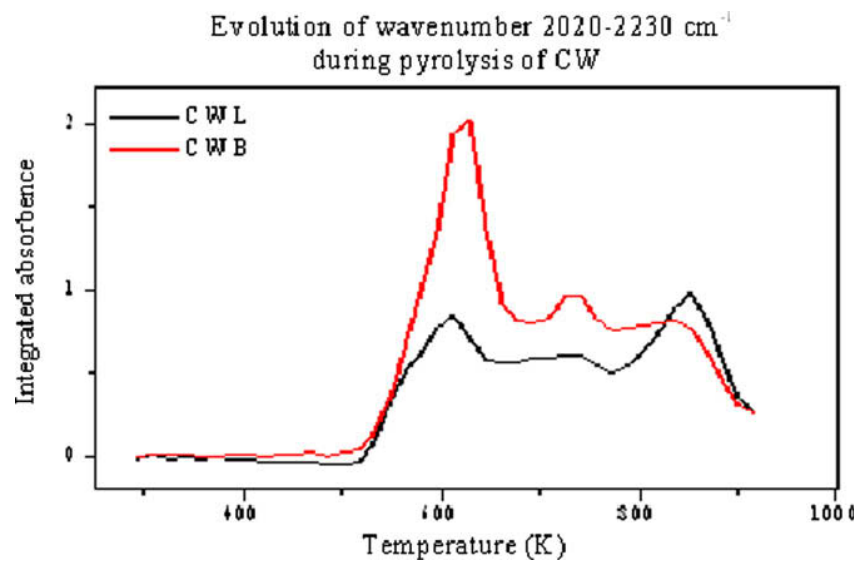

Fig. 3d. Evolution of $\mathrm{CO}$ during the pyrolysis of $\mathrm{CWL}$ and CWB.

The degradation of CWB with the release of carbon dioxide (Fig. 3c) starts around $500 \mathrm{~K}$ and reaches its maximum at $620 \mathrm{~K}$. The evolution of $\mathrm{CO}_{2}$, during the pyrolysis of $\mathrm{CWB}$ also shows two additional maxima, at 730 and $870 \mathrm{~K}$. The two first maxima ( 620 and $730 \mathrm{~K}$ ) can be assigned to the decarboxylation of the carboxylic acids. The release of $\mathrm{CO}_{2}$ at $870 \mathrm{~K}$ can probably also be assigned to the cracking of primary pyrolysis products of CWB at higher temperatures.

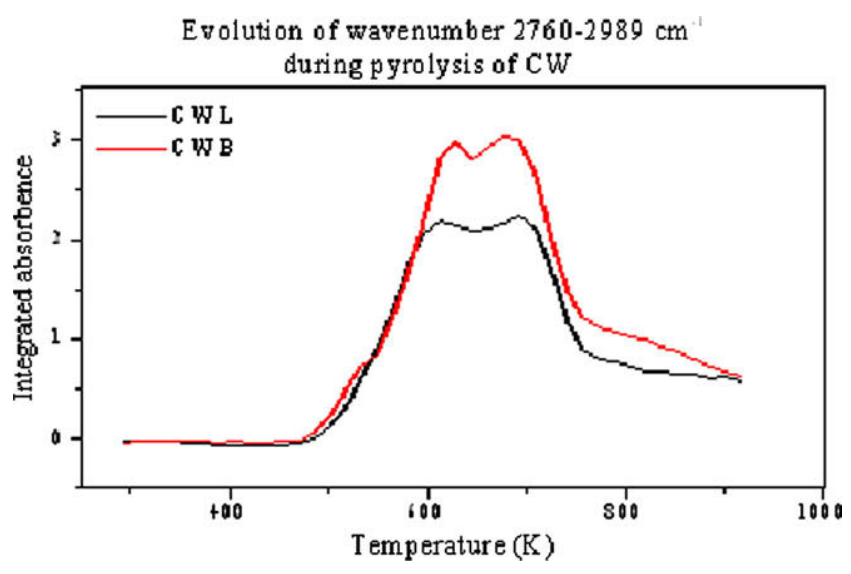

Fig. 3e. Evolution of compounds with saturated carbon-carbon bonds during the pyrolysis of CWL and CWB.

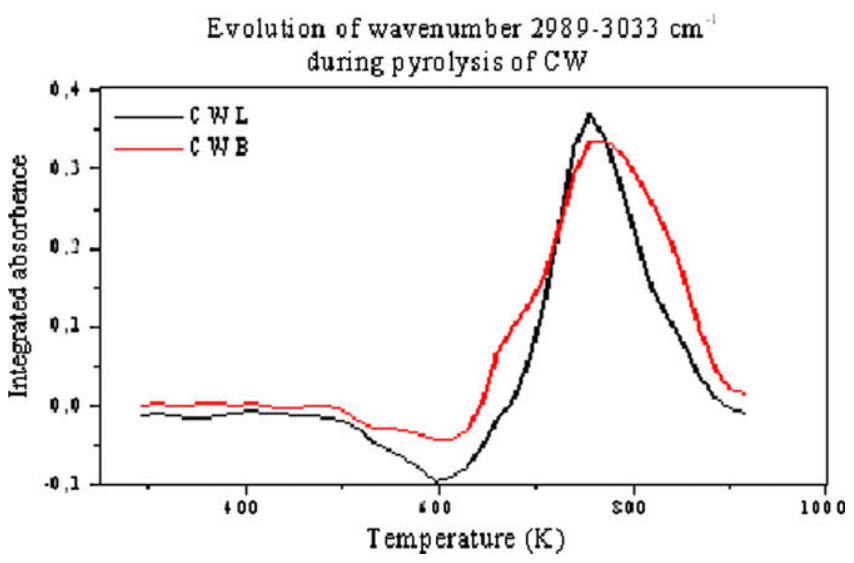

Fig. 3f. Evolution of compounds with unsaturated carbon-carbon bonds and aromatic compounds during the pyrolysis of CWL and CWB.

Carbon monoxide, detected during the pyrolysis of CWL, arises around $510 \mathrm{~K}$ and is mainly found in the $573-873 \mathrm{~K}$ temperature range with three distinct maxima at 610,730 and $850 \mathrm{~K}$ (Fig. $3 \mathrm{~d}$ ). The second and third maxima in the $\mathrm{CO}$ evolution (CWL) coincide with the shoulder and the second maximum of the $\mathrm{CO}_{2}$ evolution (CWL). Hence, these maxima could also be explained by a cracking process, a step wise breakdown of primary pyrolysis products at higher temperature.

Carbon monoxide (CWB), arises at somewhat higher temperature than $\mathrm{CO}_{2}$ (Fig. 3c for $\mathrm{CWB}$ ): at $525 \mathrm{~K}$ and is also mainly detected in the $575-875 \mathrm{~K}$ temperature range (maximum at $635 \mathrm{~K}$ ) with another minor maximum at $735 \mathrm{~K}$ which reflects the $\mathrm{O}_{2}$ depletion during the decomposition reactions.

The small absorption peaks found around 3000 and $1300 \mathrm{~cm}^{-1}$ (Figs. 2a and $2 \mathrm{~b}$, no separate Figure shown) can be assigned to methane. The formation of methane, out of the degradation of CWL, starts around $493 \mathrm{~K}$ and reaches two maxima in the 573$633 \mathrm{~K}$ temperature interval and around $773 \mathrm{~K}$. Methane production during the CWL pyrolysis at higher temperatures (around $773 \mathrm{~K}$ ) is formed as a pyrolysis product, formed under anaerobic conditions. The formation of methane, out of the pyrolysis of CWB, starts around $513 \mathrm{~K}$ and reaches a maximum at $658 \mathrm{~K}$.

The C-H stretching IR bonds, found in the 2760 and $2989 \mathrm{~cm}^{-1}$ spectral window (Fig. 3e), representing hydrocarbons moieties and chains, arise around $480 \mathrm{~K}$ to reach a maximum in the $610-710 \mathrm{~K}$ temperature range, and are similar for both plant parts. At even 
higher temperatures (723-823 K) the cracking of these saturated $\mathrm{C}-\mathrm{C}$ bonds could result in the formation of compounds with unsaturated $\mathrm{C}-\mathrm{C}$ bonds. The evolution of unsaturated compounds is shown in Fig. 3f. The release of aromatic and unsaturated compounds (2989-3033 $\mathrm{cm}^{-1}$ spectral window, typical for $\mathrm{sp}^{2} \mathrm{C}-\mathrm{H}$ stretching) starts around $645 \mathrm{~K}(\mathrm{CWL})$ and $680 \mathrm{~K}(\mathrm{CWB})$ to reach a maxima at $760 \mathrm{~K}(\mathrm{CWL})$ and $770 \mathrm{~K}(\mathrm{CWB})$.

Evidence of substituted benzene rings in the CWL and CWB pyrolysis volatiles are also confirmed in Figs. 2a and 2b. Several absorption peaks in the $800-900 \mathrm{~cm}^{-1}$ spectral window (assigned to di-substituted benzene rings) with maxima at 703 and $853 \mathrm{~K}$ for $\mathrm{CWL}$ and a maximum for $\mathrm{CWB}$ at $653 \mathrm{~K}$ are detected. IR absorption bands found in the $700-750 \mathrm{~cm}^{-1}$ spectral window, are mainly detected at temperatures higher than $773 \mathrm{~K}$ for CWB and between 653 and $923 \mathrm{~K}$ for CWL. The evolution of compounds in the spectral windows, mentioned above, also confirm that different aromatic species are formed during the pyrolysis of $\mathrm{CWL}$ and $\mathrm{CWB}$ and that they have their own unique profiles. This type of compounds can be considered as precursor for char formation.

\subsection{Characterisation of the liquid fraction of CWL and CWB}

3.5.1. Calorific values of the liquid pyrolysis products of CWL and CWB

The HHV of the liquid pyrolysis products of CWL and CWB are given in Table 6. The HHV of the CW oils (water free) varies between 20 and $24 \mathrm{MJ} / \mathrm{kg}$ and the HHV of the CW tars varies between 23 and $27 \mathrm{MJ} / \mathrm{kg}$, depending on the plant part. With respect to the HHV of the original feedstock, the oils of CWL increase $40 \%$ and these of CWB 50\%. The tars of CWL and CWB are 65\% and $45 \%$, respectively, higher than the HHV of the original feedstocks. The HHV of the condensable pyrolysis fractions of CWL and CWB are rather low compared to those of conventional liquid and gaseous fuels $[9,17]$.

\subsubsection{Composition of the bio-oil fractions of CWL and CWB}

The GC/MS chromatograms of the bio-oil and tar fractions of CWL and CWB in dichloromethane are given in Fig. 4. The GC/MS chromatograms are normalized to the highest peak (internal standard, scan number 974). The identified compounds of the bio-oil and tar fractions of CWL and CWB are summarized in Tables 7 and 8.

The qualitative composition of the bio-oils and tars in dichloromethane of $\mathrm{CW}$, show dependency on the plant part from which they originate and the conditions at which they are formed, as some compounds are not found in both bio-oils/tars. The nature of the bio-oil/tar formed during the pyrolysis of biomass is mainly dependent on: the biochemical composition of the biomass, the quantity and the composition of the ash fraction, and the moisture content [18].
Table 6

The HHV of the pyrolysis products of CWL and CWB.

\begin{tabular}{llcc}
\hline Product $(\mathrm{MJ} / \mathrm{kg})$ & Material & Calculated & Experimentally \\
\hline Oil & CWL & $23 \pm 1$ & $20 \pm 1$ \\
& CWB & $21 \pm 2$ & $23.9 \pm 0.4$ \\
Tar & CWL & $25 \pm 1$ & $25 \pm 2$ \\
\multirow{3}{*}{ Original } & CWB & $27.5 \pm 0.3$ & $23 \pm 2$ \\
& CWL & $17.2 \pm 0.3$ & $14 \pm 1$ \\
& CWB & $18.4 \pm 0.3$ & $16 \pm 2$ \\
\hline
\end{tabular}

The organic compounds in the CW bio-oils/tars, identified in dichloromethane extracts are grouped into the following classes: monocyclic aromatic compounds (benzenes, phenols and their derivates) and oxygenated hydrocarbons such as alcohols/ethers, ketones/aldehydes, carboxylic acids, nitrogen compounds and esters. To discuss the quantity of the different compounds, present in the bio-oils of CWL and CWB, the peak areas (\%) are used as an estimate. The estimated relative concentration (\%) of a compound group (e.g., ethers/alcohols) is calculated as the percentage of the sum of the identified peak areas of these compounds with respect to the total peak area of all identified peaks.

Table 9 summarizes the fractions of the different compounds in pyrolysis bio-oils and tars of CWL and CWB. The alcohol/ether compounds of CWL and CWB bio-oils make out $10 \%$ and $17 \%$, respectively, of the GC/MS identified CW pyrolysis bio-oils.

Aldehydes/ketones compounds (aromatic and aliphatic) make out each $32 \%$ resp. of the GC/MS identified CWL and CWB pyrolysis bio-oils.

Acids (aromatic and aliphatic) in the pyrolysis bio-oils of CW each make out 3\% of the GC/MS identified CW untreated pyrolysis bio-oils. But it should be noted that none of carboxylic acids (formic, acetic, propionic acid) have been detected in the $\mathrm{CW}$ bio-oils $\left(\mathrm{CH}_{2} \mathrm{Cl}_{2}\right.$ solution) by $\mathrm{GC} / \mathrm{MS}$. The $\mathrm{C}_{1}-\mathrm{C}_{4}$ carboxylic acids evaporate from the dichloromethane fraction, as has been reported in literature [19] and are therefore not detected, with this implemented technique, but are expected to be present in the bio-oil/tar mixture. These acids, as the increase in water content, also have the disadvantage of being corrosive, especially at elevated temperature [20].

The bio-oils of CWL and CWB include also a minor amount of esters ( $4 \%$ and $2 \%$, respectively) of the GC/MS identified compounds.

The aromatic compounds are divided in the aromatic hydrocarbons (and derivates) and the phenols, guaiacols and syringols. Aromatic hydrocarbons make out $7 \%$ and $1 \%$, resp. of the GC/MS identified compounds in the bio-oils of CWL and CWB, respectively. The phenolics in the CWL and CWB bio-oils make out $32 \%$ and $17 \%$, respectively, of the identified compounds in the $\mathrm{CW}$ bio-oils. The guaiacols (and derivates) of CWL and CWB bio-oils

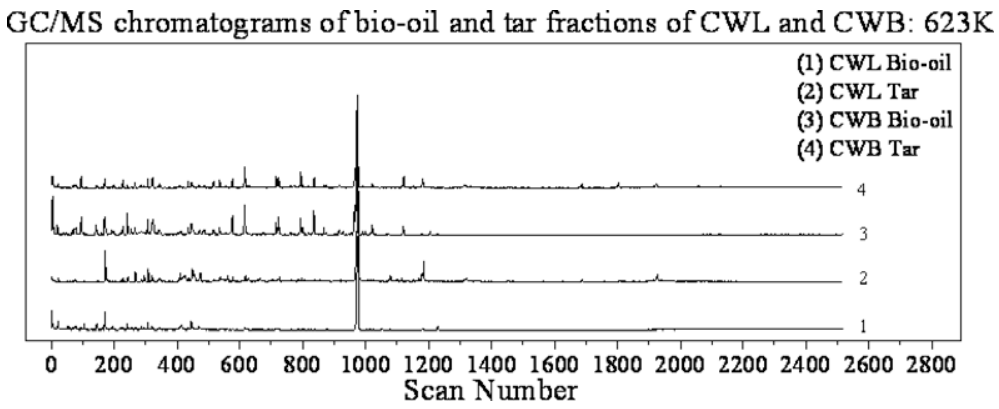

Fig. 4. GC/MS chromatograms of bio-oil and tar fractions of CWL and CWB at $623 \mathrm{~K}$. 
Table 7

GC/MS characterisation of bio-oil phases (623 K) of CWL and CWB.

\begin{tabular}{|c|c|c|c|}
\hline Scan number & Identification & Area\% CWL & Area\% CWB \\
\hline 5 & Furane methanol & 7.2 & 42.5 \\
\hline 22 & Acetoxy acetone & 9.9 & 12.5 \\
\hline 41 & Cyclopentenedione & 2.4 & 4.3 \\
\hline 51 & Styrene & 4.3 & 3.8 \\
\hline 69 & Methyl cyclopentenone & 2.7 & 6.0 \\
\hline 75 & Acetyl furane & 4.4 & 8.0 \\
\hline 79 & Butyrolactone & 3.8 & 8.9 \\
\hline 95 & Cyclopentanedione & 3.4 & 20.9 \\
\hline 105 & Cyclohexenone & 7.3 & 4.0 \\
\hline 144 & Methyl furfuraldehyde & 7.3 & 12.2 \\
\hline 160 & Methylfuroate & 1.7 & 4.0 \\
\hline 170 & Phenol & 19.9 & 21.0 \\
\hline 190 & Benzofurane & 1.6 & 3.0 \\
\hline 194 & Cyclohexandione & 4.5 & 5.9 \\
\hline 227 & Methyl cyclopentanedione & 3.8 & 10.4 \\
\hline 242 & Methyl phenol & 6.9 & 25.1 \\
\hline 266 & Methyl phenol & 3.9 & 9.9 \\
\hline 295 & Methyl phenol & 2.6 & 4.2 \\
\hline 307 & Methoxy phenol & 6.3 & 17.8 \\
\hline 320 & Methylbenzoate & 5.1 & 6.7 \\
\hline 337 & Methyl Benzofurane & 1.1 & 2.2 \\
\hline 340 & Maltol & 2.3 & 6.0 \\
\hline 343 & Phenyl ethylalcohol & 3.1 & 4.6 \\
\hline 408 & Ethylphenol & 3.8 & 3.9 \\
\hline 415 & Benzoic acid & 5.0 & 1.8 \\
\hline 445 & Benzenediol & 9.9 & 12.9 \\
\hline 482 & Hydroxymethyl furfuraldehyde & - & 5.5 \\
\hline 486 & Benzene propanol & - & 6.8 \\
\hline 518 & Methoxy benzenediol & 1.5 & 6.4 \\
\hline 536 & C2:0 methoxy phenol & 2.1 & 9.8 \\
\hline 537 & Hydroquinone & 1.9 & 4.4 \\
\hline 562 & Indole & 1.8 & 2.3 \\
\hline 579 & $\mathrm{OH}$, methyl acetophenone & 2.3 & 22.2 \\
\hline 618 & Dimethoxy phenol & 3.2 & 33.0 \\
\hline 622 & C3:1 methoxy phenol & - & 5.8 \\
\hline 628 & Dimethoxy phenol & 2.3 & 2.6 \\
\hline 632 & C3:0 methoxy phenol & - & 2.8 \\
\hline 717 & Trimethoxybenzene & - & 15.0 \\
\hline 724 & C3:1 methoxy phenol & 1.2 & 20.1 \\
\hline 802 & (Hydroxy methoxyphenyl)Propanone & 1.1 & 9.5 \\
\hline 916 & C3:1 dimethoxy phenol & - & 6.4 \\
\hline 928 & Dimethoxy hydroxybenzaldehyde & - & 4.8 \\
\hline 933 & Dimethoxy hydroxy acetophenone & - & 1.6 \\
\hline 999 & Methoxy, hydroxybenzaldehyde & - & 4.7 \\
\hline 1052 & C6:0 naphthalene & 1.7 & - \\
\hline 1121 & Hydroxy benzoic acid & - & 10.2 \\
\hline 1205 & Dimethoxy hydroxycinnemaldehyde & - & 5.2 \\
\hline 1229 & C8:0 naphthalene & 4.4 & 2.2 \\
\hline
\end{tabular}

make out $8 \%$ and $14 \%$, respectively. The syringols of CWL and CWB bio-oils make out $3 \%$ and $14 \%$, respectively. The total fraction of aromatic compounds of the CW bio-oils is also comparable, 64\% for both bio-oils. So, one could state that both $\mathrm{CW}$ bio-oils, are equally aromatic.

CWL and CWB bio-oils also enclose some nitrogen compounds.

\subsubsection{Composition of the tar fractions of CWL and CWB}

The alcohol/ether compounds of CWL and CWB make out 6\% and $12 \%$, respectively, of the GC/MS identified CW pyrolysis tars. Aldehydes/ketones compounds (aromatic and aliphatic) in the pyrolysis tars of CW make out $10 \%$ and $22 \%$, respectively. The carboxylic acids (aromatic and aliphatic) in the pyrolysis tars of CWL make out 3\%. In the CW tars, no carboxylic acids are detected. The fatty acids in the pyrolysis tars of CW consist of palmitic and linoleic acids and make $8 \%$ and 3\%, respectively, in the CWL and CWB tars.

The esters of CW make out each 5\%, of the GC/MS identified compounds in the CW tars. In contradiction to the CW bio-oils, aliphatic hydrocarbons are detected in the CW tars. The aliphatic
Table 8

GC/MS characterisation of tar phases $(623 \mathrm{~K})$ of CWL and CWB.

\begin{tabular}{|c|c|c|c|}
\hline Scan number & Identification & Area\% CWL & Area\% CWB \\
\hline 5 & Furan methanol & 4.3 & 14.3 \\
\hline 12 & Xylene & 3.0 & 4.8 \\
\hline 23 & Acetate ester & 5.5 & 5.5 \\
\hline 51 & Styrene & 3.0 & 2.2 \\
\hline 69 & Methyl cyclopentenone & 2.8 & 3.5 \\
\hline 75 & Acetyl furan & 4.2 & 5.2 \\
\hline 79 & Butyrolactone & 3.2 & 4.8 \\
\hline 95 & Hydroxy Cyclopentenone & - & 14.4 \\
\hline 111 & Methylfuranone & - & 1.8 \\
\hline 144 & Methyl furfuraldehyde & 2.5 & 4.0 \\
\hline 160 & Methylfuroate & - & 2.3 \\
\hline 170 & Phenol & 34.4 & 12.1 \\
\hline 192 & Dimethyl dihydrofuranone & - & 2.4 \\
\hline 227 & Methyl cyclopentanedione & 5.6 & 10.1 \\
\hline 242 & Methyl phenol & 6.6 & 4.3 \\
\hline 266 & Methyl phenol & 12.9 & 7.4 \\
\hline 295 & Methyl phenol & 8.7 & 3.4 \\
\hline 307 & Methoxy phenol & 14.9 & 12.2 \\
\hline 320 & Methylbenzoate & 8.1 & 5.5 \\
\hline 337 & Methyl Benzofuran & 3.4 & 2.3 \\
\hline 341 & Maltol & 4.1 & 3.5 \\
\hline 408 & Ethylphenol & 11.1 & 3.2 \\
\hline 425 & Benzoic acid & 8.9 & - \\
\hline 445 & Benzenediol & 14.7 & 8.1 \\
\hline 518 & Methoxy benzenediol & 4.0 & 9.1 \\
\hline 536 & $\mathrm{C} 2: 0$ methoxy phenol & 7.1 & 9.9 \\
\hline 562 & Indole & 8.8 & - \\
\hline 579 & $\mathrm{OH}$, methyl acetophenone & 6.8 & 12.1 \\
\hline 618 & Dimethoxy phenol & 7.9 & 23.7 \\
\hline 622 & C3:1 methoxy phenol & 3.6 & 3.8 \\
\hline 628 & Dimethoxy phenol & 5.4 & - \\
\hline 632 & C3:0 methoxy phenol & 2.6 & 3.3 \\
\hline 717 & Trimethoxybenzene & 4.3 & 14.8 \\
\hline 725 & C3:1 methoxy phenol & 7.6 & 13.2 \\
\hline 762 & C4:0 benzene diol & - & 3.1 \\
\hline 774 & C2:0 indole & 3.5 & 3.0 \\
\hline 802 & (Hydroxy methoxyphenyl)Propanone & 4.0 & 4.7 \\
\hline 837 & Dimethoxy acetophenone & 4.4 & 12.8 \\
\hline 870 & C3:1 dimethoxy phenol & 3.0 & 5.4 \\
\hline 920 & C3:1 dimethoxy phenol & 4.0 & 4.6 \\
\hline 978 & C3:0 dimethoxy phenol & 37.4 & 46.4 \\
\hline 993 & Dimethoxy hydroxy acetophenone & 2.6 & 3.2 \\
\hline 1152 & Methyl palmitate & 4.1 & 2.9 \\
\hline 1182 & Palmitic acid & 22.9 & 12.0 \\
\hline 1318 & Linoleic acid & 5.2 & 10.0 \\
\hline 1688 & Alkane & 3.8 & 5.6 \\
\hline 1925 & Stigmastandiene & 9.6 & 5.7 \\
\hline 2058 & Sitosterol & 3.4 & 3.7 \\
\hline
\end{tabular}

Table 9

Fraction of compounds in pyrolysis bio-oils and tars of CWL and CWB.

\begin{tabular}{lllll}
\hline & $\begin{array}{l}\text { Bio-oil CWL } \\
(\%)\end{array}$ & $\begin{array}{l}\text { Bio-oil CWB } \\
(\%)\end{array}$ & $\begin{array}{l}\text { Tar CWL } \\
(\%)\end{array}$ & $\begin{array}{l}\text { Tar CWB } \\
(\%)\end{array}$ \\
\hline $\begin{array}{l}\text { Ethers and alcohols } \\
\begin{array}{l}\text { Aldehydes and } \\
\quad \text { ketones }\end{array}\end{array}$ & 10 & 17 & 6 & 12 \\
$\begin{array}{l}\text { Acids } \\
\text { Esters }\end{array}$ & 32 & 32 & 10 & 22 \\
$\begin{array}{l}\text { Aromatic } \\
\quad \text { hydrocarbons }\end{array}$ & 4 & 3 & 11 & 3 \\
$\begin{array}{l}\text { Phenolics } \\
\text { Guaiacols }\end{array}$ & 32 & 2 & 5 & 5 \\
Syringols & 8 & 1 & 2 & 2 \\
N-compounds & 3 & 17 & 27 & 13 \\
& 1 & 14 & 13 & 15 \\
\end{tabular}

hydrocarbons in the CW tars make out $4 \%$ and $3 \%$, respectively, of the CWL and CWB tars. The percentage of alkanes is very low in CW tars, as reported in literature [18].

Aromatic hydrocarbons in the CW tars consist only of monocyclic aromatic hydrocarbons. These aromatics make out $2 \%$ of the 
GC/MS identified compounds in the tars of CWL and CWB. The phenolics in the CWL and CWB tars make out $27 \%$ and $13 \%$, respectively. Guaiacols of CWL and CWB tars make out 13\% and 15\%, respectively. Syringols of CWL and CWB tars, make out $19 \%$ and $24 \%$, respectively.

CWL and CWB tars also enclose nitrogen compounds, of which the concentration in the CWL tars is $4 \%$ and in the CWB tars is less than $1 \%$.

Comparing the distribution of the compounds in the CW oils and tars, it can be stated that the qualitative and quantitative composition of the oils and tars, respectively, depend on the plant from which they originate. Also, the composition (qualitative and quantitative) of the pyrolysis liquids (bio-oil and tar) of one plant part depends on the conditions under which they were collected. The CW tars consist of $71 \%$ aromatic compounds, compared to only $64 \%$ for the CW oils. The percentage of oxygenated compounds in the CW oils and CW tars are $80 \%$ and $94 \%$, respectively, of the identified compounds in the CW bio-oils and tars (at $623 \mathrm{~K}$ ).

\subsection{Characterisation of the collected volatile organic fraction of CWL and $C W B$}

The CW pyrolysis gaseous fraction of collected organics, at $623 \mathrm{~K}$ yield approximately $1 \%$. The major gaseous components, at $623 \mathrm{~K}$, in the CW pyrolysis gases are carbon dioxide, carbon monoxide and methane, deduced from the TG/FTIR data. The evolution and quantity, in which these gases are formed, show a dependency on the plant part. The CWL and CWB gas fractions show not only a difference in the major fraction of the gas phase $\left(\mathrm{CO}_{2}, \mathrm{CO}\right.$, and $\left.\mathrm{CH}_{4}\right)$, but also in the minor gaseous organic fractions. The tenax collected gas fractions of CWL and CWB differ in terms of quantity, nature and evolution.

The identification and classification of the peaks of the chromatograms of CWL and CWB in the different temperature ranges, amounts to $75 \%$ and $90 \%$ of the total collected gaseous fraction, respectively. Tables 10 and 11 give the concentrations of the different organic compounds in $\mu \mathrm{g} / \mathrm{g}$ in reference to the original feed $(0.100 \mathrm{~g})$ of CWL and CWB, respectively.

Tables 10 and 11 show that the minor organic components of the collected gaseous fraction, for CWL and CWB (at $873 \mathrm{~K}$ ), make up only 0.8 and $2.5 \mathrm{mg}$ ( $1 \%$ and $2.5 \%$ ) of the original feed, respectively. The pyrolysis gas fractions of CW, collected on tenax, in the $373-473 \mathrm{~K}$ temperature range, demonstrate that $\mathrm{CWL}$ and CWB hardly decompose in this temperature range, conform to the DTG results of CW.

Aliphatic hydrocarbons in the collected gaseous pyrolysis products of CW mainly consist of saturated and unsaturated hydrocarbon chains $\left(\mathrm{C}_{n} \mathrm{H}_{m}\right)$, (with $\mathrm{n}$ ranging between 3 and 27 , and $m=2 n+2,2 n, 2 n-2$ ), with $n$ and degree of unsaturation increasing

Table 10

Organic gas products of pyrolysis of $\mathrm{CWL}$ in $\mu \mathrm{g} / \mathrm{g}$.

\begin{tabular}{|c|c|c|c|c|c|}
\hline$\mu \mathrm{g} / \mathrm{g}$ & $\begin{array}{l}373- \\
473 \mathrm{~K}\end{array}$ & $\begin{array}{l}473- \\
573 \mathrm{~K}\end{array}$ & $\begin{array}{l}573- \\
673 \mathrm{~K}\end{array}$ & $\begin{array}{l}673- \\
773 \mathrm{~K}\end{array}$ & $\begin{array}{l}773- \\
873 \mathrm{~K}\end{array}$ \\
\hline $\begin{array}{l}\text { Aliphatic } \\
\text { hydrocarbons }\end{array}$ & 0 & 4 & 7 & 426 & 647 \\
\hline $\begin{array}{l}\text { Aromatic } \\
\text { hydrocarbons }\end{array}$ & 0.11 & 91 & 48 & 940 & 1249 \\
\hline Acids & 0.35 & 75 & 11 & 263 & 149 \\
\hline $\begin{array}{c}\text { Aldehydes/ } \\
\text { ketones }\end{array}$ & 0.89 & 166 & 209 & 278 & 240 \\
\hline Esters & $<\mathrm{DL}$ & 21 & 42 & 24 & 22 \\
\hline Ethers/alcohols & $<\mathrm{DL}$ & 73 & 70 & 149 & 122 \\
\hline $\mathrm{N}$-compounds & $<\mathrm{DL}$ & 10 & 14 & 193 & 159 \\
\hline S-compounds & $<\mathrm{DL}$ & 8 & 4 & 31 & 5 \\
\hline Phenols & $<\mathrm{DL}$ & 72 & 80 & 1068 & 1287 \\
\hline
\end{tabular}

$\mathrm{DL}=$ detection limit.
Table 11

Organic gas products of pyrolysis of CWB in $\mu \mathrm{g} / \mathrm{g}$.

\begin{tabular}{llllll}
\hline$\mu \mathrm{g} / \mathrm{g}$ & $373-$ & $473-$ & $573-$ & $673-$ & $773-$ \\
& $473 \mathrm{~K}$ & $573 \mathrm{~K}$ & $673 \mathrm{~K}$ & $773 \mathrm{~K}$ & $873 \mathrm{~K}$ \\
\hline $\begin{array}{l}\text { Aliphatic } \\
\quad \text { hydrocarbons }\end{array}$ & $<\mathrm{DL}$ & $<\mathrm{DL}$ & 15 & 1143 & 2075 \\
$\begin{array}{l}\text { Aromatic } \\
\quad \text { hydrocarbons }\end{array}$ & $<\mathrm{DL}$ & 40 & 363 & 1394 & 2560 \\
$\begin{array}{l}\text { Acids } \\
\begin{array}{l}\text { Aldehydes/ } \\
\quad \text { ketones }\end{array}\end{array}$ & $<\mathrm{DL}$ & 131 & 710 & 1453 & 591 \\
$\begin{array}{l}\text { Esters } \\
\begin{array}{l}\text { Ethers/alcohols } \\
\text { N-compounds }\end{array}\end{array}$ & $<\mathrm{DL}$ & 114 & 576 & 3484 & 1570 \\
$\begin{array}{l}\text { S-compounds } \\
\text { Phenols }\end{array}$ & $<\mathrm{DL}$ & 131 & 90 & 220 & 50 \\
\hline
\end{tabular}

$\mathrm{DL}=$ detection limit

Table 12

Minor Compound fraction (of TD/GC/MS identified compounds) and maximum temperatures of compounds in pyrolysis gases of CWL and CWB.

\begin{tabular}{lllll}
\hline & CWL $(\%)$ & CWL $T_{\max }(\mathrm{K})$ & $\mathrm{CWB}(\%)$ & $\mathrm{CWB} T_{\max }(\mathrm{K})$ \\
\hline Aliphatic hydrocarbons & 13 & $773-873$ & 13 & $773-873$ \\
Aromatic hydrocarbons & 27 & $773-873$ & 18 & $773-873$ \\
Acids & 8 & $673-773$ & 9 & $673-773$ \\
Aldehydes/ketones & 11 & $673-773$ & 23 & $673-773$ \\
Esters & 1 & $573-673$ & 2 & $673-773$ \\
Ethers/alcohols & 5 & $673-773$ & 6 & $773-873$ \\
N-compounds & 5 & $673-773$ & 2 & $773-873$ \\
S-compounds & $<1$ & $673-773$ & $<1$ & $773-873$ \\
Phenols & 30 & $773-873$ & 27 & $673-773$ \\
\hline
\end{tabular}

with temperature. Cyclopentane and cyclohexane (and derivates) are only found in the CWB collected gas fraction. The release of aliphatic hydrocarbons increases with increasing pyrolysis temperature (Tables 10 and 11). Table 12 gives the minor collected gaseous organic fraction (of TD/GC/MS identified compounds) and temperatures for maximum release of these organic emission products from CWL and CWB. These results are conforming to the TG/FTIR data. Aliphatic hydrocarbons in the collected gaseous CWL and CWB pyrolysis fractions make out each $13 \%$ of the sum of compounds (of TD/GC/MS results).

The aromatic hydrocarbons in the CW collected gaseous fractions are identified as monocyclic aromatic compounds (benzene, toluene, xylene, styrene and their derivates) and polycyclic aromatic compounds (phenanthrene, naphthalene, fluorene, anthracene and their derivates). Anthracene is only found in the CWB collected gaseous fraction. The formation and release of the monocyclic aromatic compounds, during the pyrolysis of CWL, starts at lower temperatures compared to the formation of polycyclic aromatic compounds, $373-473 \mathrm{~K}$ and $673-773 \mathrm{~K}$, respectively. This can be explained as the result of increasing cyclization reactions towards more fused aromatic compounds. The formation of the monocyclic aromatic compounds, during the pyrolysis of CWB, also starts at lower temperatures compared to the formation of polycyclic aromatic compounds, $473-573 \mathrm{~K}$ and $773-873 \mathrm{~K}$, respectively. The aromatic hydrocarbons make out $27 \%$ and $18 \%$ of the sum of TD/GC/MS collected gaseous compounds of CWL and CWB, respectively (Table 12).

The phenol fraction consists of phenol, guaiacols and syringols and their derivates. Phenol release starts at the 473-573 K temperature range during the pyrolysis of CWL and increases with increasing pyrolysis temperature (Table 10). For the pyrolysis of CWB a maximum is obtained in the $673-773 \mathrm{~K}$ temperature range (Table 11), as confirmed by the TG/FTIR results. The CWL and CWB phenolics in the collected gaseous fraction make out $30 \%$ and $27 \%$, respectively of the sum of TD/GC/MS compounds (Table 12). 
The acid fractions of the collected gaseous pyrolysis fractions of CW consist of aliphatic acids $\left(C_{1}-C_{6}\right.$-acids for $C W L$ and $C_{1}-C_{4}$-acids for $\mathrm{CWB}$ ), linoleic acid and aromatic acids (benzoic acid and their derivates). Linoleic acid is only found in the CWB collected gaseous fraction. The major part of the CW acid fraction is composed of acetic acid. The acid concentration in the CW collected gaseous pyrolysis fraction reaches its maximum in the 673-773 $\mathrm{K}$ temperature range (Table 12). The collected gaseous CWL and CWB acids are $8 \%$ and $9 \%$ of the sum of compounds, respectively.

The aldehyde fractions in the collected CW gaseous fractions are mainly composed of aliphatic aldehydes $\left(C_{3}-C_{5}\right.$-aldehydes for $\mathrm{CWL}, \mathrm{C}_{3}-\mathrm{C}_{6}$-aldehydes for $\mathrm{CWB}$ ), furfuraldehyde, benzaldehyde and derivates. The ketone fractions mainly consist of acetone, aliphatic ketones ( $C_{3}$ to $C_{6}$-ketones), furanone, acetophenone, cyclopentenone, cyclohexenone and derivates. Acetone is not detected in the CWB collected gaseous fraction. The aldehydes and ketones of the CWL and CWB gas fractions amount to $11 \%$ and $23 \%$, respectively of the sum of TD/GC/MS compounds. Aldehydes and ketones emissions during the pyrolysis of $\mathrm{CW}$ reach their maximum in the $673-773 \mathrm{~K}$ temperature range (Table 12 ). These results are in agreement with the TG/FTIR findings.

The ester fractions of CWL and CWB are composed of aliphatic esters, aromatic esters and their derivates, and make out only $1 \%$ and $2 \%$ of the collected gaseous pyrolysis fractions, respectively. CWB collected pyrolysis gaseous fraction also include furan esters. During the pyrolysis of CWL and CWB, the ester formations reach maxima in the 573-673 $\mathrm{K}$ and 673-773 $\mathrm{K}$ temperature range, respectively (Table 12), which is in accordance with the TG/FTIR data.

The alcohol fraction of the CW collected gaseous fractions includes aliphatic alcohols (butanol, pentanol, hexanol, nonenol, phytol and derivates) and aromatic alcohols (napthalenol, benzyl alcohol and derivates). The ether fractions are mainly composed of furan and benzofuran and its derivates. The CWB collected gaseous fraction differs from the CWL collected gaseous fraction that it is mainly composed of aromatic alcohols and ethers. The ether/ alcohol formation out of the degradation of CWL and CWB make out $5 \%$ and $6 \%$ of the sum of TD/GC/MS compounds, respectively, and reach maxima in the $673-773 \mathrm{~K}$ and $773-873 \mathrm{~K}$ temperature ranges, respectively (Table 12 ).

The N-compounds in the CWL and CWB collected gaseous fractions ( $5 \%$ and $2 \%$ of the sum of compounds, respectively) can be divided in aliphatic and aromatic nitrogen compounds, amines and amides. The aliphatic N-compounds consist of butane-, propane-, pentane-, hexanenitrile and their derivates. The aromatic N-compounds consist of pyridine, indole, pyrazine, benzonitrile and their derivates. The amides and amines are represented by benzamide, acetamide and trimethylamine (and derivates), respectively. Other $\mathrm{N}$ compounds in the $\mathrm{CW}$ gas phases are thiazole and succinimide. The N-compounds in the CWB collected gaseous fraction do not include amides and amines. The nitrogen compounds of the CWL and CWB collected gaseous fractions reach their maximum in the 673$773 \mathrm{~K}$ and $773-873 \mathrm{~K}$ range, respectively as seen in Tables 10 and 11.

The S-compounds are identified as methyl sulphide, thiophene (and derivates) and $\mathrm{SO}_{2}$. The $\mathrm{CWL}$ and $\mathrm{CWB}$ formation of the $\mathrm{S}$ compounds reach their maxima in the $673-773 \mathrm{~K}$ and $773-873 \mathrm{~K}$ range, respectively. The collected sulphur compounds make out less than $1 \%$ of the sum of TD/GC/MS compounds, as reported in Tables 10 and 11.

\section{Conclusions}

Combining both offline and online analytical methods for the characterization and the identification of classes of pyrolysis prod- ucts generates the most valuable information in regard of their distribution and potential use as chemicals.

It is found that mostly minor differences are found in (1) reactivity, (2) obtained yield and composition of pyrolysis products and (3) heating value during the pyrolysis experiment. These differences can be correlated with the original composition of the plant part.

Most important to notice is that, due to the low operating temperature, heavy metals are enriched in the char/ash fraction of the different pyrolysis products. This makes future valorization of heavy metal contaminated biomass and economically feasible.

A variation in nature, size, distribution and evolution of the gaseous and liquid pyrolysis compounds for different types of biomass has to be taken in account since the knowledge of the biomass matrix is really imperative in view of valorising heavy metal contaminated biomass.

However in the case of CWL and CWB, only minor differences are found and therefore there is no need to distinguish between both plant parts. In other words, the harvesting of CWL and CWB should be done at the same time when leaves are still at the branches.

\section{References}

[1] Radmanesh R, Courbariaux Y, Chaouki J, Guy C. A unified lumped approach in kinetic modelling of biomass pyrolysis. Fuel 2006;85:1211-20.

[2] Meers E, Vandecasteele B, Ruttens A, Vangronsveld J, Tack FMG. Potential of five willow species (Salix spp.) for phytoextraction of heavy metals. Environ Exp Bot 2007;60(1):57-68.

[3] Nowakowski DJ, Jones JM, Brydson RMD, Ross AB. Potassium catalysis in the pyrolysis behaviour of short rotation willow coppice. Fuel 2007;86(15): 2389-402.

[4] Cornelissen T, Yperman J, Reggers G, Schreurs S, Carleer R. Flash co-pyrolysis of biomass with polylactic acid. Part 1: Influence on bio-oil yield and heating value. Fuel 2008(87):1031-41.

[5] Cornelissen T, Jans M, Yperman J, Reggers G, Schreurs S, Carleer R. Flash copyrolysis of biomass with polyhydroxybutyrate: part 1 . Influence on bio-oil yield, water content, heating value and the production of chemicals. Fuel 2008;87(7):1031-41.

[6] Lappas AA, Samolada MC, Iatridis DK, Voutetakis SS, Vasalos IA. Biomass pyrolysis in a circulating fluid bed reactor for the production of fuels and chemicals. Fuel 2002;81:2087-95.

[7] Kalra YP. Reference methods for plant analysis. CRC Press; 1998. ISBN 157444-124-8.

[8] ASTM E1755-01. Standard method for the determination of ash in biomass. Annual book of ASTM standards, vol. 11.05. Philadelphia, PA: American Society for Testing and Materials, International; 2003.

[9] Channiwala SA, Parikh PP. An unified correlation for estimating HHV of solid, liquid and gaseous fuels. Fuel 2002;81:1051-63.

[10] Parikh J, Channiwala SA, Ghosal GK. A correlation for calculating HHV from proximate analysis of solid fuels. Fuel 2005;84:487-94.

[11] ASTM D 3286-77. Standard test method for gross calorific value of solid fuel by isothermal-jacket bomb calorimeter. Annual book of ASTM standards, part 26; 1979.

[12] Lievens C, Yperman J, Vangronsveld J, Carleer R. Study of the potential valorisation of heavy metal contaminated biomass via phytoremediation by fast pyrolysis: part I: influence of temperature and solid heat carrier on the behaviour of heavy metals. Fuel 2008;87:1894-905.

[13] Mood AM, Graybill FA, Boes DC. Introduction to the theory of statistics. McGraw-Hill; 1986.

[14] Raveendran K, Ganesh A, Khilar KC. Influence of mineral matter on biomass pyrolysis characteristics. Fuel 1995;74:1812-22.

[15] Raveendran K, Ganesh A. Heating value of biomass and biomass pyrolysis products. Fuel 1996;75:1715-20.

[16] Pütün EA, Uzun BB, Apaydin E, Pütün E. Bio-oil from olive industry wastes: pyrolysis of olive residue under different conditions. Fuel Process Technol 2005;87:25-32.

[17] Montes-Morán MA, Menéndez JA, Fuente E, Suárez D. Contribution of the basal planes to carbon basicity: an abinitio study of the $\mathrm{H}_{3} \mathrm{O}^{+}$interaction in cluster models. J Phys Chem B 1998;102:5595-601.

[18] Diebold JP. A review of the chemical and physical mechanisms of the storage stability of fast pyrolysis oils. NREL/SR-570-27613; 2000.

[19] Oasmaa A, Kuoppala E. Fast pyrolysis of forestry residue 3. Storage stability of liquid fuel. Energy Fuel 2003;17:1075-84.

[20] Czernik S, Bridgwater AV. Overview of the applications of biomass fast pyrolysis oil. Energy Fuel 2004;18:590-8 